\title{
SMART APPLICATIONS AND THEIR IMPACT ON RAISING THE PERFORMANCE EFFICIENCY OF ADMINISTRATIVE BUILDINGS IN EGYPT
}

\author{
Shaima Abdel-Majeed Abdel ${ }^{\text {, Majeed Ibrahim }}{ }^{2, *}$ \\ ${ }^{1}$ Architecture department - Faculty of Engineering - Al-Azhar University
}

\begin{abstract}
energy crisis facing the world with its impact, as architects, we must find new solutions and innovative alternatives in which smart technologies are used to provide other sources of energy production instead of relying on non-emerging traditional energy sources that consume a lot of the budget, especially in light of the rising population and increasing consumption, With the possibility of obtaining energy from renewable sources such as solar and wind energy, hence the trend towards interest in the application of smart, energy-saving and energy-generating buildings capable of accommodating the needs of buildings by assessing their performance and functional efficiency and the impact of technological aspects on the behavior of users of administrative buildings and its reflection on the functional performance of users. .

Keywords

SMART APPLICATIONS- EFFICIENCY OF ADMINISTRATIVE BUILDINGS- ENERGY SAVING
\end{abstract}

\section{Introduction:}

In light of the energy crisis facing the world with its impact, as architects, we must find new solutions and innovative alternatives in which smart technologies are used to provide other sources of energy production instead of relying on nonemerging traditional energy sources that consume a lot of the budget, especially in light of the rising population and increasing consumption, With the possibility of obtaining energy from renewable sources such as solar and wind energy, hence the trend towards interest in the application of smart, energy-saving and energygenerating buildings capable of accommodating the needs of buildings by assessing their performance and functional efficiency and the impact of technological aspects on the behavior of users of administrative buildings and its 
reflection on the functional performance of users. Through the user's satisfaction and comfort, the objectives of the research: The main objective of the research is to shed light on the possibilities of smart technologies in saving energy and producing energy by making use of the various renewable energy sources within the administrative buildings, and from it the main objective branches into the following secondary objectives:

1- Study the main elements affecting the design of administrative buildings.

2- Examine the smart elements of finishing administrative buildings externally to make them smart energy-producing buildings and the source of energy distribution to neighboring buildings to enter a material return in which the administrative process is developed, and its reflection on the functional performance of users through satisfaction and the user oasis in it.

3- An applied analytical study of some models of Egyptian architecture that have acceptable attempts to implement the concept of smart building, which emphasizes Egypt's attempt to communicate with global architecture and keep pace with the development of the times.

\section{Research problem:}

\section{The research problem is summarized as follows:}

1- The energy crisis has ballooned at the local and global levels and has caused major crises inside buildings in a wide area. 
2- The administrative buildings need a large amount of energy that must be provided at the present time and in a greater way for the future.

3- The needs of the buildings being administered in addition to containing at the same time a large number of dowry students. From the above, the research problem crystallizes in this question: What are the images of smart architecture that can be used to save and rationalize energy consumption in administrative buildings in Egypt?

\section{The future of electric power generation in Egypt:}

The negative indicators indicate that the energy gap in Egypt is increasing in terms of its size according to the data of the same bulletin issued by the Electricity Utility and Consumer Protection Regulatory Agency. The data indicate a continuous increase in consumption, so we find that Egypt's share of solar energy generation is very small despite the fact that Egypt has the highest rates of radiation The solar system in the world (up to $3000 \mathrm{kWh} / \mathrm{m} 2$ per year) as it represents one of the countries in the solar belt region that is most suitable for solar energy applications.

Wind energy contributes less than $2 \%$ to the current generated electrical energy despite the abundance of wind resources in the establishment of future wind farm projects in desert lands that are ineligible for inhabitants with high average wind speeds ranging from 8-10 meters / second, especially in the Gulf of Suez and the Gulf of Aqaba region. Numerous studies indicate that the electricity generated 
from wind sources represents the best opportunity for renewable energy in Egypt to reach competitive electricity prices compared to fuel and gas. The hydro-power stations also contributed to the generation of $11.2 \%$ of the electrical energy generated in Egypt. Plants were built to generate electricity from gas resulting from wastewater treatment (such as: the Jabal Asfar plant with a capacity of 23 megawatts).

This is in addition to the possibility of generating 1000 megawatts of agricultural waste, thus despite Egypt's possession There are reserves from all these sources, but due to the growing use of them and the high cost of extracting them, Egypt will face a deficit in covering its needs from those sources, and this is a source of concern as it stems from the fact that Egypt does not produce enough electricity so that the energy consumed in Egypt represents about\% 92. 5 Of them are nonrenewable energy, and thus Egypt seeks to restore the balance between oil and gas production with uses after overcoming the economic difficulties that faced the oil and gas sector in the coming years and increasing the percentage of energy generated from renewable energies to $20 \%$ of the total electrical energy generated in Egypt. The development of the best amount of electrical energy consumed in Egypt in the year $2020 \mathrm{AD}$, so that hydropower contributes about $6 \%$ in addition to $12 \%$ of wind energy and $2 \%$ of solar energy.

\section{Fundamentals of Designing Low Energy Buildings:}


The idea of designing low-energy buildings is an idea that can meet all of its energy requirements at low cost, by:

1- Protection from solar radiation and heat gain.

2- Rationalization of energy deposition from outside to inside and vice versa.

3- It works to generate energy from renewable energies.

4- Maintains the internal energy of the building.

5- Using modern technologies to reduce consumption.

\section{Smart building concept:}

It is the building that is based on serving the beneficiaries of it including administrators, employees and visitors through an integrated system and it mainly depends on the extent of smart technologies and modern systems connected to each other.

\section{Applications of smart technologies that can be used to rationalize energy} consumption:

The progress of smart technologies and their applications in all areas of life and architecture has clearly affected through their influence on design, construction and finishing methods, and smart technologies have made it possible to integrate them with different systems, such as communication, lighting, heating and 
cooling systems, to give the building and urban space the ability to centralize control.

They are systems that respond to environmental influences, such as temperature, light condition, humidity, or electric and magnetic fields with certain changes in some variables with the aim of: achieving modern technology and human comfort, and the following are new ideas for producing energy from outside the building:

\section{1- Photovoltaic units:}

The facades and roofs of the building are reinforced with photovoltaic units to work on converting solar energy into electrical energy and placing it on residential buildings in a decent manner providing for the aesthetics of both the residential unit or at the level of public buildings within the closed urban complexes.

\section{2- Decorated double facades that filter the polluted air:}

A double façade was used at Manuel Hospital in Mexico City to help absorb air pollution. The façade is composed of ornate units with polygonal patterns such as crystal that lead to a geometric shade on both sides, so that the facade consists of a material called "prosolve", a material coated with titanium dioxide that acts as a filter. To purify the air and get rid of emissions, toxins, etc. before entering the building, it works as a natural light filtering system and obtaining solar 
energy, thus effectively saving the energy bill in the hospital through climate and light control.

\section{3- Photovoltaic glass technology:}

It is considered the development of technology, curtain walls and providing it with photovoltaic cells to store energy and convert it into a giant display screen, where photovoltaic cells are added to the glass panels to allow the passage of light and turn into excessive energy for the display screen, so the photovoltaic cells store the solar energy during the day and at nightfall they use the energy stored on it In the presentation of the media, it also reflects the climatic conditions of the day.

\section{4- Smart Mashrabiya:}

They are dynamic interfaces built on the basis of technology that simulates the movement of the human eye so that they contain cells that are exactly like the lenses of photographic cameras of different sizes, and were designed to take into account the possibility of miniaturizing and enlarging their openings so as to allow the entry of light in a mechanically linked way to the intensity of brightness, and is characterized by the following:

- Provides energy, lighting, and human comfort for the users of the vacuum.

- Keep the mini cool. 
- They let in light from the sun's rays.

- It is considered an alternative to the Arab Mashrabiya, as it can be used in administrative buildings to provide daylight inside the space.

The applied study to reach energy efficiency and renewable energy in administrative buildings:

The applied study of Egyptian architecture aims to identify the extent to which Egyptian architecture has benefited from the information revolution, modern technological revolutions and ideas after the third millennium (twenty-first century architecture), specifically its position on the rapid technical development in the field of construction and the extent of the response of the local experience to the idea of the "smart administrative building" And the extent to which Egypt keeps pace with global progress in reaching a smart architectural product, by conducting an applied analytical study of some models of Egyptian architecture that have acceptable attempts to implement the concept of smart building, which emphasizes Egypt's attempt to communicate with global architecture and keep pace with the development of the modern era.

\section{The methodology for selecting applied projects is as follows:}

A group of projects are selected that have a major role in adding new to modern architecture in terms of the advanced technology used and through its interaction and response to functional, environmental and contemporary architectural factors. Models are chosen according to the level of their technical and 
environmental progress that can rise to the level of global smart architecture, and projects are selected in different regions and in a different climate environment to identify the effects resulting on them within the change in the environment and architecture standards in them and that the selected projects were built in years The last ten buildings should include modern and liberal architectural thinking based on modern architectural trends and the selection of projects that bear one or more features of smart buildings that were mentioned before. And choosing projects that are famous for their absorption of high technological capabilities, smart systems and their compatibility with the environment

\section{Methodology of the applied study:}

Investigation of the objectives of the applied study. The following methodology for the field study may be adopted through the process of monitoring and documenting the selected local administrative buildings, so that the process includes the following :

The definition of the building (the design problem, the architectural description, the building intelligence features) is done through the use of documents, information and plans from the engineering offices designed for each administrative building from the selected administrative buildings, until we finally reach the desired results from them, and from within the buildings in the Smart Village was chosen 
A- The Ministry of Communications and Information Technology building) It is an administrative government building affiliated with one of the administrative governmental institutions in the Arab Republic of Egypt, as it is built with specific fixed elements that do not change as a purely administrative function, in order to study the systems of smart windows and means of shading and photovoltaic cells and the use of forming the outer envelope in shading and shading from Through the following points:

- Ecological autonomous interfaces were used to allow the entry of solar rays in a directed manner provided with types of optical sensors.

- Glass blinds were used with facades that integrate with the reflective facades of solar rays made of reflective glass with transparency to meet the solar angles.

- Horizontal umbrellas were used from the kosour above the dormer windows of the facade and repeated in a number of floors with different designs, shapes and specifications of advanced technology materials that prevent shading, prevent direct exposure and light glare and maintain air quality around the mini. .

- The use of double-faced covers for the four faces consisting of two layers of double-glazed panels, between them an air gap of $60 \mathrm{~cm}$ width to make an air insulating vacuum.

- The use of low heat conduction materials between the glass layers such as: Filme Sun Protect to increase the thermal efficiency to reduce the thermal loss in winter and summer gain without affecting the light transmitted inside. 
B- A field study of the Technology Investment Zone in Maadi - The Ministry of Communications and Information Technology Building (4 MB), which is the second specialized investment zone in Egypt, and it is a cooperative project between several government agencies, including the Ministry of Communications and Information Technology, the Ministry of Investment and the Cairo Governorate

- The amount of shade increases as the building is more complex, and the smaller the proportion of the exterior surface of the building exposed to weather conditions in relation to the mini depth, the lower the thermal loads.

- As a result of taking a single direction in all floors, this leads to a decrease in the solar rays and an increase in the amount of shading for each floor, and the higher the height of the building, the more affected the buildings adjacent to the village buildings, which affect the natural lighting directed inside after studying the angles of inclination of the sun throughout the year.

- The use of double casings for the four fronts, Double Layer, consisting of two layers of double glazing panels, between which there is an air space in which gas is placed with a width of $60 \mathrm{~cm}$ to create an air-insulating vacuum and a path for the shading function. 
- Insulating foam is used to maintain the temperature of the building inside the use of an insulating wall so that the internal and external temperature differences do not occur, which depend on the use of shading units as external curtains on the windows in order to reduce the heat load and increase the efficiency of isolating the nets from the outside surroundings.

\section{Results:}

1- Energy is the main focus of thinking for all the various modern environmental design trends, as it is the common factor on which the efficiency and suitability of each environmental design direction is measured with the building to be designed.

2- Although smart buildings are usually more expensive than traditional buildings, they are more economical in the long run, as the actual cost of the total life-cycle of the building (Total Life-Cycle) is much lower than the cost of the normal building life due to the severe energy savings and Ease of maintenance and control of systems and developing them easily with the development of technology.

3- Building intelligence is not determined by the extent of development of the technologies used in the independent building systems, but is measured by the extent of the integration between the different building systems.

\section{Recommendations :}


Important recommendations are made that must be taken into account to better evaluate buildings that would reach a certain level and this is the aim of the study and all the following studies, through:

\section{A- Research Recommendations:}

1- The roofs of buildings must be used as green roofs through sound and thermal insulation, and they should be used as an external administrative environment or as a space for sports and entertainment activities, by shading them with wooden ceilings or the like.

2- Building blocks must be formed to improve the aesthetic appearance and form sources of attraction for visitors.

3- The use of modern control methods for lighting and appropriate ventilation inside spaces, such as photoelectric or temporal control.

4- Natural lighting must be used, and automatic sensors and control should be used to measure the needs of the lighting spaces when there is a lack of natural lighting, such as control bags when opening or closing windows.

5- Green building materials that are recyclable and energy-saving with no or limited carbon dioxide emissions should be used in the manufacturing phase and the operating period

\section{B- Future recommendations:}


1- Developing custom software programs to keep up with new developments in smart building technology to be supportive in the process of evaluating the performance of smart buildings in Egypt.

2- Conducting a study on the efficiency of administrative smart buildings and their impact on the productivity of the occupants, their productivity rates, environmental comfort and the extent of satisfaction it provides to them.

3- Carrying out a study of the possibility of applying smart systems in the study of existing administrative buildings, so that smart systems can be increased in those existing buildings and catch up with the technological development in the era of information technology, in a study that focuses on the benefits of economic smart buildings and their benefits to the work environment in administrative buildings and the owner and the environment in general.

\section{References:}

1- Ministry of Electricity and Renewable Energy, Annual Report for the year 2014-2015 AD, The Holding

Company for Electricity Egypt, http: / / www. moee. gov. eg

2- Adel Yassin Muharram, Architecture and Energy Handbook, Energy Planning Authority, 1998 AD

3- Annual Report, 2014-2015 AD, Egypt Ministry of Electricity and Energy Renewed, Holding Company

Electricity Egypt http: / / www. moee. gov. eg

4- Nirvana Osama Hanafi, Ph.D., "Smart Building Performance Assessment in Egypt. Based on Computational

Cognitive Tools", Faculty of Engineering, Cairo University, 2015

5- Lamis Sayed Mohamedi Abdel Qader, The Role of Technology in Developing Traditional Architectural Elements, Master Thesis, Faculty of Engineering, Cairo University, 2011

6- Noha Ezz El-Din, Smart Technologies used to rationalize energy consumption within the movement spaces 
of commercial centers - The Smart Mall, Master's Thesis, Faculty of Engineering, Cairo University, 2014.

7- Muhammad Al-Sayed State, "Smart Technology in Contemporary Architecture", Master Thesis, Faculty of Engineering, Ain Shams University, 2005 AD

8- Abd Al-Rahim Hassan Al-Shehri, "Building Technology and its Role in Achieving Thermal Comfort Inside Architectural Spaces", Master Thesis, Faculty of Engineering, Cairo University, 2008 AD.

9- Hazem Mohamed Nour Afifi, "Design Considerations for Rural Housing from the Perspective of Environmental Engineering and Energy Self-sufficiency," a research paper, The Third Conference for the Development of the Egyptian Countryside, Shebin El-Kom, September 22, 2001.

10- Mohamed Abdel Fattah Ahmed, "The Economics of Environmental Design", PhD thesis, Cairo University, Faculty of Engineering, 2007

11- http://b.vimeocdn.com/ts/285/262/285262399_640.jpg

12- $\quad$ http://egyptera.org/ar/elec gen egy.aspx

13- www.SmartElevation.com

14- www.you.are-here.com/europe/printmedia.jpg

15- http://theenergysolutiongroup.com 